\title{
A Gestão Escolar em uma Escola Indígena do Rio Grande do Norte: Concepções e Práticas
}

\section{School Management in an Indigenous School in Rio Grande do Norte: Conceptions and Practices}

\author{
Creusa Ribeiro da Silva Lelis*ab; Givanildo da Silva ${ }^{\text {bc }}$

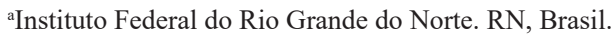 \\ bUniversidade Federal da Paraíba, Programa de Pós-Graduação Stricto Sensu em Educação. PB, Brasil. \\ 'Universidade Federal de Alagoas. AL, Brasil. \\ *E-mail: creusa.lelis@ifrn.edu.br
}

\begin{abstract}
Resumo
A pesquisa teve como objetivo apresentar as concepções e as práticas da gestão escolar em uma Escola indígena, no município de Canguaretama, no estado do Rio Grande do Norte. A metodologia esteve pautada na abordagem qualitativa e o estudo de caso, como técnica de pesquisa. Os dados foram coletados através da entrevista semiestruturada com 6 profissionais da Escola. Como resultados, foi possível perceber que a concepção vivenciada pela comunidade não apresenta as características da gestão democrática, uma vez que as comunidades local e escolar não estão presentes nos processos decisórios e de planejamento da proposta pedagógica.
\end{abstract}

Palavras-chave: Gestão Escolar. Conselho Escolar. Escola Indígena. Escola Pública.

\begin{abstract}
The research aimed to present the concepts and practices of school management in an indigenous school, in the municipality of Canguaretama, in the state of Rio Grande do Norte. The methodology was based on the qualitative approach and the case study as a research technique. Data were collected through semi-structured interviews with 6 school professionals. As a result, it was possible to realize that the conception experienced by the community does not present the characteristics of democratic management, since the local and school communities are not present in the decision making and planning processes of the pedagogical proposal.
\end{abstract}

Keywords: School management. School board. Indigenous School. Public school.

\section{Introdução}

A pesquisa teve como objetivo apresentar as concepções e as práticas da gestão escolar em uma Escola indígena, no município de Canguaretama, no estado do Rio Grande do Norte. Esta pesquisa considerou como universo empírico de investigação a Escola Municipal Indígena João Lino da Silva, situada na Comunidade do Catu.

A opção por estudar essa Escola justificou-se pelo fato de ser a única Escola indígena no estado do Rio Grande do Norte, bem como representar um espaço de luta e de resistência pela manutenção e transmissão da cultura e da identidade indígena daquela Comunidade.

\section{Material e Métodos}

A abordagem do estudo foi caracterizada como qualitativa, uma vez que "[...] responde a questões muito particulares. Ela se preocupa, nas Ciências Sociais, com um nível de realidade que não pode ser quantificado, ou seja, ela trabalha com o universo de significados, motivos, aspirações, crenças, valores e atitudes" (MINAYO, 2010, p.21-22). Outro aspecto característico da pesquisa qualitativa foi a maneira como os dados foram descritos. A descrição das pessoas, das situações e dos acontecimentos, através de palavras e imagens, usando os números de modo pouco significativo. Para isso, foi importante capturar a perspectiva dos participantes, ou seja, a maneira como os entrevistados encaravam as questões que estavam sendo focalizadas. Ao considerar esses diferentes pontos de vista dos participantes, este estudo de caráter qualitativo permitiu esclarecer o dinamismo interno das situações, geralmente inacessível a quem estivesse de fora (BOGDAN; BIKLEN, 1994).

A opção pelo estudo de caso, como método de investigação, ocorreu em função da natureza de pesquisa considerada neste estudo. Nessa lógica, compreende-se este estudo de caso a partir de uma definição técnica apresentada por Yin (2010, p.39), o qual pode ser entendido como "[...] uma investigação empírica que investiga um fenômeno contemporâneo em profundidade e em seu contexto da vida real, especialmente quando os limites entre o fenômeno e o contexto não são claramente evidentes".

A coleta de dados foi realizada através de entrevistas semiestruturadas. De acordo com Gil (2008, p. 109), a entrevista pode ser definida "[...] como a técnica em que o investigador se apresenta frente ao investigado e lhe formula perguntas, com o objetivo de obtenção dos dados que interessam à investigação". Nesse sentido, a entrevista foi considerada como uma forma de interação social, através da 
qual foi possível interagir com as pessoas que compunham a dinâmica da Escola investigada. Para Yin (2010), a entrevista é uma das fontes mais importantes de informação para o estudo de caso, como também se torna essencial para evidenciar assuntos humanos e eventos comportamentais.

Foram entrevistadas seis pessoas: um diretor, e cincoprofessoras, as quais são representadas, respectivamente, pelos códigos VMAS, LCSC, OS, RAL, DCBS e JMS. Dentre os critérios considerados para escolha desses sujeitos, estavam: pertencessem à Comunidade do Catu; fossem maiores de idade (acima de 18 anos); de ambos os sexos; estivessem envolvidos com a gestão administrativa e pedagógica da Escola na qual foi realizada a pesquisa.

Para a realização das análises, foi utilizada a contribuição teórica e metodológica da "Abordagem do Ciclo de Políticas", a qual foi formulada por Stephen J. Ball (1989; 1994); Richard Bowe, Stephen Ball e Anne Gold (1992) e tem sido utilizada como um referencial analítico consistente para políticas educacionais, em uma análise micropolítica da Escola, a partir de métodos modernistas sujeitos à teorização pós-estrutural.

Diante dessa compreensão, a escolha pelo Ciclo de Políticas, enquanto referencial teórico-metodológico, encontrou justificativa na afirmação de Mainardes (2007, p. 27), de que essa abordagem "[...] destaca a natureza complexa e controversa da política educacional, enfatiza os processos micropolíticos e a ação dos profissionais que lidam com as políticas no nível local”, indicando, dessa forma, “[...] a necessidade de se articularem os processos macro e micro na análise das políticas educacionais".

O texto está estruturado em duas partes que se completam, além da introdução e das considerações finais. Na primeira, dialoga-se sobre a gestão escolar e suas características, a partir do que os dispositivos legais apresentam acerca da temática. Na segunda, evidencia-se a gestão escolar e suas nuances por meio da realidade da Comunidade do Catu, no município de Canguaretama, no estado do Rio Grande do Norte.

\section{Resultados e Discussão}

\subsection{A gestão escolar no contexto da legislação}

A concepção de gestão escolar defendida nos dispositivos legais que regulamentam a educação brasileira é a gestão democrática. A constituição Federal de 1988, a Lei de Diretrizes e Bases da Educação Nacional, 9.394, de 20 de dezembro de 1996, e o atual Plano Nacional de Educação, Lei 13.005 , de 25 de junho de 2014, salientam que a concepção que deve vigorar no processo de organização da Escola pública é a gestão democrática, cuja participação dos diferentes segmentos é o ápice para o seu desenvolvimento.

Nesse cenário, a gestão escolar torna-se uma dimensão complexa, política e em construção, uma vez que sua vivência depende de outros elementos, advindos da gestão educacional.
De acordo com Lück (2013, p. 17), “a gestão educacional, apresenta-se em caráter amplo e abrangente do sistema de ensino, e a gestão escolar referente à escola". Os dispositivos legais não tornam a gestão democrática obrigatória nas redes e sistemas de ensino, apenas orientam qual a concepção de gestão para o contexto brasileiro.

Mediante esse contexto, é válido apresentar os desafios que são inerentes ao processo de vivência da gestão escolar, uma vez que a execução da gestão democrática nas Escolas públicas esbarra na estrutura política e nos processos da política educacional. De acordo com Silva, Silva e Santos (2016, p. 542):

[...] as diretrizes da LDB/1996 em relação à participação de todos que compõem a unidade educativa veiculam mecanismos da própria comunidade escolar e local no planejamento do projeto pedagógico, a fim de melhorar a qualidade da realidade educacional, por meio de participação e de processos decisórios, sob a ótica de diversos segmentos. Outro aspecto significativo é a ênfase nos conselhos escolares, na forma de controle social, numa perspectiva de deliberação das práticas escolares, propiciando maior autonomia e descentralização das ações planejadas pela comunidade escolar.

As proposições apresentadas pelos pesquisadores mostram os caminhos designados pela LDB/1996 para a existência da gestão democrática nas Escolas públicas, a elaboração coletiva da proposta pedagógica e a existência do Conselho Escolar. Desse modo, “a presença dos vários segmentos nos processos políticos da Escola pública favorece a constatação de princípios que são defendidos pelo modelo de gestão democrática, destacando-se a descentralização, a participação e a autonomia" (SILVA; SILVA; SANTOS, 2016, p.546). Nessa lógica, esbarra-se no desafio da participação dos diversos segmentos nas decisões pertencentes à Escola, mesmo sendo uma defesa constitucional.

Para analisar o modelo de gestão escolar, adota-se o termo "gestão" como sinônimo de administração, de governança, portanto, refere-se à organização da rotina, do trabalho da Escola como um todo, envolvendo as suas diversas dimensões e áreas: administrativa, pedagógica e financeira. Conforme define Ferreira (2001, p.306), “[...] gestão é administração, é tomada de decisão, é organização, é direção. Relaciona-se com a atividade de impulsionar uma organização a atingir seus objetivos, cumprir sua função, desempenhar seu papel", sob a liderança do gestor ${ }^{1}$ ou da equipe gestora.

Ainda sobre o conceito de gestão, Ball (1994) o define como um conjunto de práticas e de formas mais intensas e precisas de controle sobre os processos de ensino, um modelo generalizado de funcionamento, uma forma de definir as relações de poder em termos da vida cotidiana dos homens. De acordo com esse ponto de vista, o autor apresentou a ideia de que a "[...] gestão constitui uma concepção abrangente de controle organizacional. Perdura como corpo teórico 
suscetível de aprendizagem e internalização por líderes e como um conjunto de práticas a implementar, afetando os gestores e dirigidos" (BALL, 1994, p. 158, tradução nossa). Em concordância com o autor, observa-se que a gestão desempenha um papel fundamental no processo de reconstrução contínua do trabalho educativo na Escola.

De acordo com Libâneo (2001), existem três concepções distintas de gestão escolar: a concepção técnico-científica, a concepção autogestionária e a concepção democráticaparticipativa, para as quais corresponde uma atuação específica do gestor no espaço escolar. Segundo Libâneo (2001), a concepção técnico-científica é aquela que se manifesta, por exemplo, no modelo de gestão da qualidade total, de caráter piramidal, com ênfase no poder centralizado, na divisão técnica do trabalho escolar, visando à racionalização do trabalho e a eficiência dos serviços escolares, dando maior importância às tarefas do que às pessoas.

A concepção autogestionária baseia-se na responsabilidade coletiva e recusa qualquer tipo de norma e sistema de controle, priorizando as inter-relações mais do que as tarefas, a ausência de direção centralizada e a acentuação da participação direta e por igual de todos os membros da instituição. A concepção democrática-participativa é a que envolve uma relação orgânica entre direção e todos os outros segmentos da Escola prevalecendo objetivos e decisões construídas coletivamente que, posteriormente, serão assumidas por cada membro em sua especificidade de forma organizada e flexível.

A concepção de gestão democrática, priorizada neste estudo, na visão de Lima (2011, p.78), “é consagrada como direito e como instrumento privilegiado de realização da democracia", coerente com os princípios democráticos, a formação para a cidadania e o respeito à diversidade, regulamentados pelos documentos legais que normatizam a educação brasileira. Com base nesses aspectos, chamou atenção a definição de gestão democrática apresentada por Spósito (2002, p.55), a qual se apresenta como "um instrumento de transformação das práticas escolares", que implica na formulação de um novo jeito de organizar a Escola, articulado a um projeto pedagógico, construído especialmente pelos que fazem e conhecem o cotidiano escolar.

Nessa perspectiva, é possível asseverar que a gestão democrática de uma Escola se fundamenta em princípios importantes, quais sejam: a autonomia, a descentralização e, prioritariamente, a participação. Castro (2009) e Lück (2013a) reafirmaram que, na perspectiva democrática, a gestão deve ser compreendida como um espaço de descentralização do poder, com tomada de decisão compartilhada, para a construção de autonomia e, sobretudo, a participação política, na articulação com a comunidade escolar.

Sobre o princípio da autonomia de uma Escola pública, de acordo com Libâneo (2001, p.115), significa "ter poder de decisão sobre seus objetivos e suas formas de organização, manter-se relativamente independente do poder central, administrar recursos financeiros". Nesse sentido, representa a liberdade de ação, do poder de decisão, da coordenação das suas atividades, da contratação e pagamento de pessoal, administração dos recursos, independente do controle e regulação do poder público. A este respeito, Silva (2018, p. 99) ponderou que a autonomia "[...] apresenta-se relativa e restrita, em que o processo de organização e gestão escolar como um todo está condicionado às orientações fixadas pela política nacional de educação, [...] dependente do poder central e da gestão pública municipal".

Outro aspecto importante da gestão democrática é a descentralização, que se caracteriza pela divisão do poder, das tarefas, no âmbito da gestão e organização do trabalho na Escola, o que significa tirar das mãos do diretor escolar o poder decisório e a condução do trabalho da Escola. Conforme afirmação de Abranches (2003, p.18), "a descentralização só existe no momento em que as decisões locais possuem uma certa autonomia e emanam de uma coletividade e não do Estado". Ou seja, o aspecto principal a ser considerado no processo de descentralização é que este pode incentivar e criar oportunidades para a participação social, através do deslocamento dos centros decisórios. Para tanto, essa descentralização só faria sentido se também houvesse descentralização dos recursos que chegam à Escola, a fim de realizar os projetos e as atividades definidas pelo coletivo escolar.

Diante dessas assertivas, deve-se considerar a descentralização como um meio de favorecimento da participação no espaço público escolar democrático, quer dizer, a descentralização só se torna possível através da participação, a qual representa condição relevante para a construção da gestão democrática (ABRANCHES, 2003). De acordo com as afirmações de Bordignon e Gracindo (2001), além da autonomia e da descentralização, a participação também constitui condição relevante para que a gestão seja considerada democrática. Dessa forma, defende-se que não se pode afirmar que existe construção democrática no âmbito da Escola pública, sem a ação participativa das pessoas que a integram, pois existe uma relação inseparável entre democracia e participação.

\subsection{Desvendando a realidade da Escola Indígena no Catu...}

A Escola Municipal Indígena João Lino da Silva não tem o processo de escolha direta para gestor. Assim, todos os líderes que a Escola já teve são oriundos de indicação política do poder público local. A comunidade indígena fez movimentos junto à Secretaria Municipal de Educação para que pudesse ser efetivada a eleição direta para gestor escolar, mas até o momento da realização da pesquisa não foi concretizada essa ação. A atual gestora foi indicada no início de 2016 pelo poder municipal, ocupando o espaço de JLS, o qual voltou para sala de aula na própria Escola.

No tocante ao processo eleitoral como forma de provimento do cargo de gestor escolar, VMAS nunca declarou interesse por essa possibilidade, nem abordou a temática da 
gestão democrática, durante as entrevistas. Contudo, algumas professoras entrevistadas, igualmente reconheceram o esforço da diretora, principalmente para aquisição de material didático e na capacidade de ouvir a equipe docente, os quais representam elementos que indicam interesse em trabalhar de forma democrática e dialógica, com dedicação, na luta pela melhoria da Escola. A este respeito, seguem, alguns desses depoimentos:

Eu reconheço o esforço da gestão que está agora na Escola. Reconheço mesmo, que o que tá podendo fazer, tá buscando fazer, né? Pela Escola. Tá ouvindo, tá conseguindo ouvir, né? Os professores. Uma gestão que ela ouve, não é uma gestão que só fala, que só coloca, ouve realmente, né? A opinião dos professores (Professora da Educação Infantil, LCSC).

Sobre a direção da Escola, ninguém é perfeito, todo mundo tem suas falhas assim como nós professores também temos nossas falhas. Existe as falhas, mas é o de menos, porque são falhas pequenas, assim, da parte da direção. [...] eu digo assim, até pelo motivo de recursos, mas que é uma falha assim, que muitas vezes não vem dela, vem da Secretaria de Educação, porque se referindo assim ao lanche, a merenda dessas crianças, como aqui tem muita criança carente. Então, olhe hoje mesmo, VMAS ligou para o setor da merenda: Tragam lanche para a Escola. Esse mandou porque ela pediu, porque tinha criança com fome e não tinha nada hoje na Escola (Professora OS).

Eu vejo assim, muita dedicação da parte dela, né? Do querer buscar, do querer melhorar, de buscar o que não se tinha, o que não tinha na Escola. Então, eu vejo ela bastante cobrando, indo atrás de ventiladores, de coisas que é direito da Escola, é direito da criança, atrás de quadro, de giz e tudo mais. Então, essa parte ela não deixa faltar, ela sempre tá em cima. Então o que ela puder, ela tá lá (Professora auxiliar RAL)

A gestão tá querendo mudar, né? Mudar um pouco do que era, tá fazendo de tudo. Eu vejo que ela é muito esforçada, procura tá sempre na rua cobrando, porque lá, como eu disse, tem que tá cobrando direto pra ver se chega alguma coisa na Escola. E ela tá aí atuando, sempre indo lá, cobrando, que eu achei que não fosse assim, né? Eu também me enganei um pouco, achei que esse ano fosse ser bem melhor (Professora de reforço escolar DCBS).

Embora nenhuma das professoras entrevistadas tenha feito referência à necessidade de uma gestão democrática na Escola, cabe refletir sobre essa temática por dois motivos. Primeiramente, porque a Resolução n. 5/2012, em seu título IV, que trata do Projeto Político-Pedagógico das Escolas Indígenas, trouxe, na primeira seção sobre os currículos da Educação Escolar Indígena, o artigo 16 que apresenta:

A observação destes critérios $^{1}$ demandam, por parte dos sistemas de ensino e de suas instituições formadoras, a criação das condições para a construção e o desenvolvimento dos currículos das escolas indígenas com a participação das comunidades indígenas, promovendo a gestão comunitária, democrática e diferenciada da Educação Escolar Indígena (BRASIL, 2012, p. 9).

Além de a gestão democrática estar referenciada na Resolução n. 5/2012, também representa um dos oito princípios citados no projeto político-pedagógico da Escola, os quais deviam embasar o ensino ministrado na referida instituição de ensino. Ademais, está descrita no capítulo 14 da LDB/1996 e, de modo semelhante, no segundo capítulo do Regimento Escolar, que aborda os objetivos educacionais, cujo terceiro título foi destinado à gestão democrática, pontuado da seguinte forma:

Art. $9^{\circ}$ A gestão democrática da Escola Municipal Indígena João Lino da Silva, com abrangência dos princípios de coerência, pluralismo de ideias e concepções pedagógicas e corresponsabilidade da comunidade escolar, far-se-á mediante:

I - participação dos seus profissionais na construção, implementação e avaliação da proposta pedagógica;

II - participação dos diferentes segmentos da comunidade nos processos consultivos e decisórios por meio do Conselho de Escola (REGIMENTO ESCOLAR, 2015, p. 4).

O Conselho Escolar surgiu no Brasil no contexto da década de 1980, quando se verificava o processo de abertura política e a propagação das ideias de democratização do país. Assim, na visão dos autores Silva (2018), Libâneo (2001) e Paro (2001), com estes conselhos, esperava-se contribuir para a democratização das relações no interior da Escola pública. A função principal dos Conselhos Escolares é contribuir nos processos decisórios e na organização da Escola, configurandose como o Conselho Escolar é o órgão máximo da instituição.

Perante essa conjuntura, é relevante refletir sobre a afirmação de Souza (2012), de que, para o processo de construção da gestão democrática escolar, é fundamental considerar a participação dos seus diversos segmentos, sobretudo, através das instâncias colegiadas. De acordo com Galina e Carbello (2008), essas instâncias colegiadas são espaços de representação de todos os segmentos da Escola: discentes, docentes, pais e comunidade. Com a utilização desses espaços, fruto da conquista da própria comunidade, a gestão democrática ganha força e pode transformar a realidade escolar. Esse sucesso depende das relações estabelecidas entre os segmentos e a direção da Escola, como também do acompanhamento contínuo de todos, nas ações implementadas na rotina escolar.

Segundo Veiga (2005), essas instâncias colegiadas são representadas pelo Conselho Escolar, pela Associação de Pais, Mestres e Funcionários, pelo Conselho de Classe, pelo Grêmio Estudantil, entre outras. Entende-se que cada uma dessas esferas deve ser consolidada na criação e no fortalecimento de mecanismos democráticos de discussão e decisão, assumidos pelo coletivo escolar. Diante da importância desses órgãos, Abranches (2003, p. 54), afirma que os “órgãos colegiados têm possibilitado a implementação de novas formas de gestão por meio de um modelo de administração coletiva, em que todos participam dos processos decisórios e do acompanhamento, execução e avaliação das ações nas unidades escolares". Para tanto, deve envolver as esferas administrativas, financeiras e

2 No sexto parágrafo do artigo 15, o qual alude sobre a organização curricular das Escolas indígenas, a Resolução n. 5/2012 afirma que devem ser observados 9 (nove) critérios. Por isso, a referência da observação de tais critérios no artigo 16. 
pedagógicas.

Apesar de órgãos colegiados serem fundamentais para efetivação de gestão democrática, a fim de que haja compartilhamento de decisões e informações na administração escolar, foi identificado que na Escola pesquisada existia apenas o Conselho Escolar. Conforme anunciado no PPP (2015), em um dos tópicos sobre a organização atual da instituição, o Conselho Escolar tem funções consultivas, deliberativas, fiscalizadora e mobilizadora para assegurar a efetiva participação da comunidade escolar. Compete a este conselho: participar do planejamento global das ações pedagógicas), visando melhorias para o processo de aprendizagem e de desenvolvimento dos segmentos que compõem a Escola.

O Conselho da Escola também foi descrito no Regimento Escolar (2015), constituindo o primeiro capítulo, sobre os órgãos colegiados, e compondo o título terceiro, relacionado à Gestão Democrática. Além desse primeiro capítulo, havia um segundo, sobre as instituições escolares, que tratava da função, do Estatuto e do Caixa Escolar, o qual:

[...] é uma Sociedade Civil, com personalidade jurídica de direito privado, sem fins econômicos, representativa da comunidade escolar, instituída por legislação específica para receber e administrar os recursos financeiros destinados à Escola, transferidos por órgãos federais, pela comunidade, por entidades privadas, e recursos resultantes de campanhas escolares (REGIMENTO ESCOLAR, 2015, p.5).

Ainda constava, no Regimento, que o Caixa Escolar era registrado em Cartório de Registro Civil de Pessoas Jurídicas. Constava também a natureza (consultiva, deliberativa e fiscalizadora), os princípios (equidade, coerência, respeito às normas e à legislação vigente, assim como ao pluralismo de ideias e busca pela integração da comunidade escolar com a sociedade), a composição (diretor como membro nato, representantes dos professores, estudantes, pais ou responsáveis e dos servidores que exerciam atividades administrativas na Escola) e as competências do Conselho Escolar, quais sejam: prestar contas, opinar sobre o PPP, sugerir modificações no Regimento e convocar Assembleia Geral, quando necessário.

Segundo a diretora VMAS, o Conselho da Escola era formado pela gestora, na qualidade de presidente, três representantes dos pais, três docentes, uma auxiliar de serviços gerais e dois representantes da Comunidade que não tinham filhos na Escola. Nesse sentido, cabe fazer a defesa de que os Conselhos Escolares e sua articulação com a implantação da gestão democrática é um dos mecanismos propícios para a concretização de uma Escola pública, na qual atenda as demandas internas e luta por melhores condições de qualidade na oferta do ensino. Os estudos de Marques (2007), Abranches (2003), Werle (2003) e Silva (2018) salientam que o Conselho Escolar constitui um órgão máximo de representação, composto por integrantes da escola, no apoio da gestão escolar, que deve ser potencializado com o propósito de uma prática democrática.

Para Marques (2007, p.81), o Conselho Escolar compreende uma instância organizadora da escola, por meio da qual educador, pais, alunos e comunidade têm o direito de participar da gestão tomando decisões, encaminhandoas e avaliando-as, portanto, um elemento fundamental na construção de uma escola pública democrática. Isto implica em repensar a estrutura de poder da Escola, na perspectiva da sua descentralização e da socialização.

Em linhas gerais, dentre as atribuições do Conselho Escolar, podiam ser citadas: elaboração do Regimento; convocação de assembleias gerais da comunidade escolar; participação na construção do calendário escolar; aprovação do plano de aplicação dos recursos financeiros que chegam à Escola; fiscalização das gestões administrativa, pedagógica e financeira da unidade escolar; garantia da participação da comunidade escolar na definição do PPP daEscola; participação no processo de escolha do diretor da Escola; participação nas negociações, discussões e soluções de problemas cotidianos da Escola que sejam de interesse coletivo; deliberação sobre alterações no currículo escolar, respeitando o disposto da LDB/1996; dentre outras (BRASIL, 2006).

Nesses termos, foi possível observar que o Conselho da Escola Municipal Indígena João Lino da Silva não funcionava de acordo com o estabelecido na legislação, pois ele e sua representatividade não participaram da elaboração do Regimento e do PPP da Escola, a julgar pelo desconhecimento dos conselheiros sobre estes documentos. Esses aspectos descaracterizavam uma gestão democrática. Além disso, não havia reuniões entre seus membros de modo regular, haja vista não ter acontecido reuniões no decorrer do referido ano, das quais foi possível participar, enquanto se construía os dados deste estudo. Essa informação foi ratificada por um depoimento de JLS, ao avaliar sua gestão, enquanto ex-diretor:

Então, quando você tinha que resolver questões burocráticas da Escola, acompanhar o sistema, a produção pedagógica dos professores, como gestor, algo ia ficar a desejar. E uma das questões que ficava a desejar era o Conselho da Escola. Esse, a gente só se reunia pra elaborar atas. Ainda bem que eles vinham, participavam das reuniões, não é? Pra se fazer alguma alteração no prédio, eles tinham que fazer essa apreciação e aprovação. Esse ano [referência a 2017], o Conselho da Escola não se reuniu nenhuma vez, não teve nenhuma reunião. Não sei como é que vai ser apresentada as demandas, não é? (Professor, antigo gestor e Cacique da Comunidade do Catu, JLS.

Para esclarecer um pouco mais sobre essas reuniões do Conselho Escolar, VMAS relatou que estas “[...] aconteciam semestralmente para prestação de contas e que, nos últimos quatro anos não funcionou bem". Ainda acrescentou que “[...] em 2017 só aconteceu a primeira reunião no início do ano letivo, onde foi feita a prestação de contas e a mudança de presidente [saiu JLS e entrou VMAS]" (Diretora VMAS. Entrevista concedida em abril de 2017). Essa preocupação com a gestão dos recursos financeiros, enquanto responsabilidade 
do Conselho Escolar, também foi manifestada por JLS, quando disse que "[...] é uma obrigação da gestão da escola, uma obrigação da comunidade escolar, do conselho do Caixa Escola tá fiscalizando a aplicação desses recursos" (Professor, antigo gestor e Cacique da Comunidade do Catu, JLS).

Necessário se faz enfatizar que, diferente das funções do Conselho Escolar, existe a Unidade Executora (UEX), igualmente conhecida por Caixa Escolar, a qual também pode ser considerada um mecanismo democrático de gestão, que atua em conjunto com o Conselho Escolar. Em conformidade com as afirmações de Silva (2018, p.14), a "Unidade Executora (UEX) da escola, é o espaço onde se define, discute e delibera, especialmente, sobre a utilização dos recursos financeiros da escola, oriundos da União, Estados ou Municípios". Segundo Silva (2018), a UEX é uma instituição jurídica, de direito privado, sem fins lucrativos, geralmente, a composição da UEX é a mesma do Conselho Escolar, em que os segmentos da Escola estão representados.

Embora a gestão financeira seja uma das funções do Conselho da Escola e da UEX, conforme estabelecido no Regimento Escolar, ela não deve ser a sua única preocupação, uma vez que esse órgão colegiado também é responsável por acompanhar e apoiar a rotina da gestão da Escola, com atribuições pedagógicas e administrativas. Dessa forma, a orientação deve ser para o Conselho Escolar reunir-se sempre que necessário e em caráter extraordinário, convocando toda a comunidade a participar, sobretudo, os conselheiros, representantes dos segmentos escolares, que teriam direito a voz e voto nas assembleias. Essas reuniões devem ser relatadas em Livro de Ata, assinada pelos presentes, constituindo-se, assim, em um documento importante para a Escola (SILVA, 2018)

Sobre os últimos quatro anos de funcionamento do Conselho da Escola João Lino da Silva, período (2013-2016) que correspondeu à gestão escolar de JLS, foi, segundo ele, uma época difícil. A Escola não contava com secretaria nem coordenação pedagógica, o que ocasionava um acúmulo de funções para o gestor, além das questões burocráticas (normas, ofícios, programas e projetos) que, em suas palavras, causavam-lhe dores de cabeça:

Eu falei: Olha, não dá pra JLS ser gestor, cuidar de toda a questão burocrática dessa Escola e, ainda mais com essa Escola com todos os problemas que tem de Caixa Escola, com certeza vai levar muito tempo para legalizar esse Caixa Escola. E eu nunca fui bom nessas questões burocráticas. Isso sempre doeu a cabeça (Professor, antigo gestor e Cacique da Comunidade do Catu, JLS)

Perante essa declaração, JLS reconheceu a sua dificuldade de lidar com os aspectos burocráticos da gestão escolar, o que, consequentemente, trouxe prejuízos à administração do Conselho da Escola. Foi possível comprovar esta assertiva, quando JLS relatou sobre o funcionamento do Conselho Escolar durante a sua gestão, e ele assim se pronunciou:

Se reunia, mas não ordinariamente. Não conseguia ter as reuniões ordinárias, não é? A cada ano a gente conseguiu se reunir, no máximo, duas vezes por ano, em cada semestre, né? E uma das questões era porque a gente tinha que preencher uma meta no sistema do MEC, né? E as opiniões tinham que ser do Conselho. Então, a gente tava se reunindo duas vezes por ano pra tá cumprindo essa meta. Era uma falha, eu acho que eu, como gestor, não conseguia abranger toda essa questão (Professor, antigo gestor e Cacique da Comunidade do Catu, JLS).

Conforme as afirmações de Silva (2018), muitos Conselhos Escolares atuam de forma burocrática e descomprometida com a Escola, realizando reuniões apenas para legitimarem decisões já prontas e assinarem o livro de Ata. Segundo a autora, agindo assim, estes conselhos "[...] não realizam um trabalho coletivo producente, no sentido de nortear processos escolares em direção à prática democrática, ao crescimento do coletivo escolar, usando da transparência e compartilhamento de informações de forma dialogada" (SILVA, 2018, p.201). Deste modo, fazia-se necessário incorporar uma pauta de discussão ampliada e envolver a representação de diversas vozes com direito ao voto nas resoluções das questões da Escola. Com isso, o Conselho Escolar estaria contribuindo para a afirmação dos interesses coletivos e o desenvolvimento dos processos de decisão e de autonomia.

Perante essas considerações, nota-se que o Conselho da Escola João Lino da Silva tinha uma atuação inconstante, tanto que uma das professoras entrevistadas admitiu o seu desconhecimento dessa instância colegiada, afirmando que “[...] tinha muita coisa lá que a gente desconhecia, lá do Regimento, até mesmo do Conselho Escolar, muita coisa" (Professora de Reforço Escolar, DCBS. Entrevista concedida em julho de 2017).

Efetivar uma gestão democrática e participativa nos ambientes públicos escolares não é uma tarefa fácil, tampouco rápida. Neste espaço educativo de investigação, esse processo precisava ser construído e aprendido, a partir de um maior envolvimento dos seus membros em todas as ações desenvolvidas na Escola, principalmente através da atuação do seu Conselho Escolar.

Além da descrição desse aparato legal que regulamenta a gestão democrática na Escola Municipal Indígena João Lino da Silva, outro motivo que despertou o interesse em discutir sobre o assunto neste estudo foi a luta empreendida pelo antigo gestor, JLS, em defesa dessa perspectiva de gestão escolar. Essa é uma demanda escolar existente desde 2014, durante o $1^{\circ}$ Seminário de Educação Indígena no estado do Rio Grande do Norte, realizado na referida Escola. Além desses aspectos, a discussão sobre a gestão democrática também se justifica por ser a concepção de gestão escolar defendida nesta pesquisa, por acreditar que uma gestão precisa ser construída de forma democrática, com a participação de todos nas decisões coletivas da Escola.

Nesse momento do debate, em que se fez uma reflexão sobre essa busca por uma gestão democrática, entendendo-a como um dos efeitos provocados pelas políticas públicas 
para a educação indígena na Escola João Lino da Silva, principalmente buscando o embasamento legal e a reivindicação proposta por uma liderança na Comunidade do Catu, é importante tornar visível a compreensão do que representava uma gestão democrática na Escola investigada. Nas entrevistas, JLS sempre defendeu essa forma de gerir, principalmente para evitar que a direção fosse exercida por pessoas de cargo comissionado, as quais não poderiam administrar a Escola com a autonomia necessária. Interessante registrar o que JLS entendia por autonomia em uma Escola indígena:

Então, além de trabalhar o currículo diferenciado, ter autonomia, que essa autonomia era de grande importância, porque essa autonomia garantia o direito dessa Escola sentar e elaborar seu calendário anual específico, respeitando suas datas comemorativas, respeitando seus momentos de colheita, respeitando tudo isso. Até então, não, as escolas tanto da Aldeia Catu como do Município recebem um calendário do Município, da Secretaria de Educação. Tá aqui o calendário olha, duzentos dias letivos, é desse jeito aqui e vocês tem que cumprir. Hoje, não. Hoje, a Escola tem que sentar ano a ano (Professor, antigo gestor e Cacique da Comunidade do Catu, JLS).

Embora tivesse feito referência à importância de um calendário específico para as escolas indígenas, como garantia da autonomia escolar, o entrevistado reconheceu, com certa tristeza, que no ano de 2017 não houve reunião para discutir sobre o calendário e a inclusão das datas comemorativas específicas da Comunidade. Segundo ele, a Escola “[...] talvez esteja seguindo esse ano um calendário do ano anterior, né? Dos anos anteriores, que não muda muito pouco por causa das datas que são fixas, né?". Entretanto, disse ser “[...] importante que se discutam algumas ações que possam tá sendo inovadas dentro do calendário" (Professor, antigo gestor e Cacique da Comunidade do Catu, JLS. Entrevista concedida em setembro de 2017). Em virtude de relacionar a gestão democrática à autonomia da Escola, JLS pontuou o seguinte:

Então, isso é importante pra uma escola indígena, essa autonomia. A autonomia de poder optar, de poder decidir ações como momentos de interação professor, aulas como formação continuada. Tudo isso uma escola indígena ela tem autonomia pra fazer, sem precisar que o Município dê aval ou não. Essa autonomia é importante pra uma escola indígena. Então, uma escola vinculada direta só a ação do Município, ela não fala por si, daí a necessidade da gestão democrática. As escolas do município não têm gestão democrática. $\mathrm{O}$ Estado tem gestão democrática fragilizada, mas tem (Professor, antigo gestor e Cacique da Comunidade do Catu, JLS).

Foi constatado, na rotina da Escola, que havia uma autonomia relativa, durante o período em que a pesquisa estava sendo realizada. Eram funcionários prestadores de serviço, sem vínculo empregatício, que trabalhavam com medo de ser dispensados a qualquer momento e com salários atrasados. Além disso, uma precariedade na disposição de material e merenda escolar. Certamente, eram elementos que dificultavam o trabalho de uma gestão escolar democrática, autônoma e de qualidade.
Silva (2018) também elencou uma série de problemas que tem inviabilizado o trabalho de um gestor democrático na Escola pública. Dentre alguns aspectos, ela enumerou: Escolas com estruturas precárias; falta de recursos materiais e didáticos adequados; salas de aulas com muitos alunos; salários precários dos profissionais; ausência de boa formação e qualificação profissional para educadores; escassez de tempo e espaço disponível para estudo e planejamento na Escola; demandas de projetos e atividades; inexistência de concurso público; pouco envolvimento dos pais na Escola; cultura escolar autoritária; resistência à mudança por parte dos profissionais desqualificados e desestimulados; altos índices de adoecimento nos profissionais que atuam na rotina da Escola, entre outros.

Essas questões inviabilizam a construção de uma Escola pública que possa atender as demandas locais e tenham como ponto de partida a participação dos diferentes segmentos nos processos decisórios. De um modo geral, a Escola em análise ainda necessita de maiores investimentos do setor público para a concretização de uma Escola de boa qualidade, tendo como referência a estrutura, a merenda escolar, recursos materiais e didáticos, profissionais efetivos, formação dos profissionais e pagamento dos salários regulares.

Além desses aspectos, foi importante reconhecer também as condições concretas, desfavoráveis nas Escolas, que se constituíam em obstáculos para o trabalho do gestor comprometido com a gestão democrática e participativa. Silva (2018) destacou que as Escolas ainda apresentam uma estrutura hierarquizada, presa às leis e questões burocráticas (normas, ofícios, programas e projetos) e o controle do poder externo. O resultado dessa configuração política provocava insatisfação, sentimento de frustração e, até mesmo, o distanciamento da comunidade escolar, no seu envolvimento com os processos escolares, afastando a possibilidade de uma gestão democrática, com a participação como elemento determinante desse processo gestor.

Em face do exposto, foi significativo o destaque feito por Ball (1989, p. 91, tradução nossa), de que “[...] o papel do diretor é fundamental e decisivo para a compreensão da micropolítica da escola. As responsabilidades legais do diretor o situam numa posição única de autocracia admitida", ou seja, assumia grande poder na administração escolar. Foi possível comprovar esse aspecto, durante a investigação realizada, quando VMAS caracterizou a gestão ou, em outras palavras, que tipo de liderança ela se considerava. VMAS respondeu da seguinte forma:

Eu sou uma líder que gosto de me adequar a todos os meus funcionários, à equipe, né? Você tem que saber formar sua equipe, se você não se adequar a ela, ela não vai se adequar a você. É difícil. Primeiro eu tenho que me adequar a eles pra eles juntar-se a mim. E não é fazer o que eu quero, porque eu deixo bem claro: livre pra trabalhar. Todo mundo sabe o que fazer, não precisa eu tá mandando, mas se você não fizer, eu mando, porque eu sei que precisa. Para eu ser boa não é isso. Pra mim, ser boa não é isso, deixar você tá sentado aqui, numa área aqui e um banheiro sujo, sabendo que tá. Então eu 
vou e peço pra você fazer. O problema é esse. Eles sabem que eu peço e que é assim (Diretora VMAS).

Esta afirmação fez lembrar uma assertiva de Ball (1989, p. 99, tradução nossa), na qual afirmou: "a confiança do diretor depende de que façam um bom trabalho, espera-se que assumam a responsabilidade de seus assuntos, que não pedem nem requerem a intervenção do diretor, mas também que não vá além de sua esfera limitada de responsabilidade". Em outras palavras, cada um devia ser responsável por desenvolver as suas atividades. Com isso, vinha a necessidade de manter assegurada a importância nas relações pessoais entre diretora e membros do grupo, criando um sentido de obrigação mútua e diminuindo as queixas em relação à gestão escolar.

A este respeito, Ball (2001) chamou o gestor de "herói cultural", cujo trabalho envolvia a insinuação de atitudes e de culturas, "[...] nas quais os/as trabalhadores/as se sentem, eles/as próprios/as, responsabilizados/as e, simultaneamente, comprometidos/as ou pessoalmente envolvidos/as na organização" (BALL, 2001, p. 108-109, tradução nossa) da Escola. Cabe ratificar esse aspecto através do relato de uma das professoras entrevistadas, quando declarou que "[...] a gestão não se faz só, né? Porque se for por nós, pra ministrar, pela nossa vontade, a Escola, não taria nessa situação, mas tem melhorado, né? Hoje eu vejo uma paz, uma preocupação pelo trabalho escolar, uma participação, mas com o funcionário" (Professora JMS).

Diante das observações realizadas, percebe-se que a gestora desempenhava o estilo interpessoal de liderança, conforme as elucidações feitas por Ball (1989, p. 98, tradução nossa), o qual, “[...] como o termo sugere, a ênfase está na interação pessoal, contato face a face entre o diretor e sua equipe". Como resultado desse perfil, uma das entrevistadas destacou que “[...] minha relação com essa abençoada aí, graças a Deus, a minha relação com a gestora, sempre foi muito boa, pelo menos com VMAS, a gente sempre teve um trabalho muito bom" (Professora MPS. Entrevista concedida em abril de 2017). Dessa forma, um diretor com essa característica, “[...] quase sem exceção, desenvolverá tudo o que pretende graças às suas relações, não necessariamente com o pessoal em forma coletiva, mas individualmente" (BALL, 1989, p. 99, tradução nossa).

Outra professora também mencionou mais um aspecto na sua boa relação com a gestora, afirmando que "[...] sobre a direção eu não tenho o que dizer não, até porque quando eu tô com dúvidas, eu peço ajuda a VMAS que hoje é a gestora" (Professora OS. Entrevista concedida em maio de 2017). Sobre esse aspecto, Ball (1989, p. 98, tradução nossa) explicou que "[...] existe uma preferência pelas negociações e acordos individuais que, em alguns aspectos, ajusta-se a uma definição profissional da relação professor-diretor". Ou seja, “[...] os membros do grupo são estimulados a considerarem-se profissionais autônomos cujos problemas e queixas podem e devem ser resolvidos um a um com o diretor". Nesse tipo de relação, foi constatado que havia uma reduzida importância para as reuniões formais e a tomada de decisões mais sérias, pois tudo era resolvido através das conversas informais entre diretora e equipe docente.

No tocante a essa informalidade na relação entre a diretora e a equipe docente da Escola investigada, é relevante considerar que VMAS buscasse uma relação harmoniosa com a comunidade escolar. Contudo, as decisões referentes à Escola devem ser tomadas no coletivo e discutidas abertamente. Essa atitude não impede que cada membro da equipe assuma as suas funções no trabalho que lhe compete, assim como a existência de uma coordenação e avaliação ordenada da execução das decisões, diferenciando funções exercidas no ambiente escolar. Nesse sentido, é preciso ponderar que a figura da direção expressa poder no contexto escolar, necessitando demonstrar diálogo, empatia, persuasão, diplomacia e direção na organização da Escola.

Ainda sobre esta informalidade nas relações entre gestora e professores, Ball (1989) realçou que o uso do termo informalidade é significativo. $\mathrm{O}$ estilo interpessoal se orienta baseado na informalidade nas relações e o uso de redes informais de comunicação e consulta. Isto gera e mantém uma sensação de confiança e obrigação. Contudo, essa relação informal que fazia uso de conversas nas redes sociais não se constituía em um aspecto positivo para todos os entrevistados:

A relação é muito boa. Comigo assim, nunca tiveram o que dizer. Se tiver alguma coisa que a gestão esteja achando exagerado em certas coisas, vem pra mim e conversa. Não é conversa terceirizada. E eu nunca gostei dessa parte terceirizada ou usar instrumentos online. Nunca gostei, né? Eu acho que todas duas gestões eles me conheceram muito bem também, devido à clareza que eu coloco as coisas. E quando tivesse alguma coisa que eu acho que deveria mudar, deveria ser assim, eles chegam pra mim. Diz: Olha, vamos conversar? Vamos conversar. Olha, isso aconteceu assim, assim. Você poderia fazer dessa maneira? Pronto. E dá tudo certo (Professora da Educação Infantil, LCSC).

Sobre o uso das redes sociais na Comunidade, JLS relatou o seguinte:

Não temos grupos específicos do movimento indígena pra gente tá jogando as informações, mas temos grupos que são de interesse, não é? No caso aqui da Aldeia, a gente tem o 'Por um Catu sem males', quando a gente bota informações que são importantes pra o movimento indígena, da Comunidade como um todo. Tem um grupo de Saúde Indígena, que joga informações relacionadas à saúde dos povos indígenas, eventos, vacinas. E participamos também do Facebook, não é? Então, no Facebook a gente tá atualizando, tá pegando as questões, novas demandas, porque estão em contato com indígenas de todo o Brasil. Quer dizer, a gente tá tentando acompanhar de todas as formas esse mundo globalizado, porque se nós povos indígenas não entendermos esse funcionamento, fica muito difícil da gente conseguir avançar pelos direitos coletivos, não é? (Professor, antigo gestor e Cacique da Comunidade do Catu, JLS).

A partir dessas declarações, infere-se que a gestão da Escola pesquisada procurava manter uma imagem de democracia, mas permaneciam invisíveis as fontes de poder 
na figura da diretora e na administração municipal. Embora a gestora sempre estivesse receptiva às ideias do grupo, havia uma subordinação à Secretaria Municipal de Educação.

\section{Conclusão}

As proposições sinalizadas, por meio do estudo de caso, na Comunidade do Catu, contribuíram para a reflexão de que a vivência da gestão escolar é uma dimensão complexa e necessita da participação ativa de todos os partícipes para a construção de uma escola democrática, inclusiva e referenciada socialmente. Os apontamentos, através das vozes dos participantes da pesquisa, foram incisivos no discurso sobre os desafios e os dilemas para a concretização do papel do gestor escolar que visa à democratização das decisões democráticas nos âmbitos administrativo, pedagógico e financeiro.

No tocante à existência do Conselho Escolar, os dados coletados mostraram que a Escola não efetiva as funções do órgão máximo, sendo apenas um colegiado que se reúne para prestação de contas, descaracterizando a sua função e as suas possibilidades na concretização de uma Escola pública, com uma concepção de gestão democrática. Essa realidade possibilita refletir que os desafios postos no contexto da educação são intensos, uma vez que tratar de participação e de envolvimento coletivo requer uma sensibilidade dos dilemas, dos conflitos e da relevância da Escola, enquanto patrimônio coletivo e cultural.

As reflexões postas foram importantes para o diálogo e a abertura de novas pesquisas sobre a área, especialmente em locais peculiares, como o Catu, em Canguaretama, que tem uma especificidade, uma tradição de lutas, de resistências e de culturas marcada na história de seu povo e da sua comunidade. Os estudos sobre a gestão escolar e o processo de organização escolar são relevantes, pois caracterizam o epicentro das políticas educacionais instauradas no contexto escolar local e evidenciam os caminhos formativos que estão sendo configurados ao longo dos tempos, através das políticas postas no cenário social e educacional.

Por fim, cabe salientar que a gestão escolar é um campo aberto. O debate sobre a área se faz necessário a fim de contribuir com as múltiplas visões sobre o processo de organização da Escola, seus conflitos, seus desafios e suas histórias. A educação engloba diferentes dimensões currículo, formação docente, financiamento, qualidade da educação, estrutura, avaliação da aprendizagem - e todas essas demandam organicidade na concretização da concepção de educação pautada nas práticas vivenciadas. Diante dessa configuração, é válido que todos os participantes da Escola sejam atuantes e possam estar engajados na construção de um ambiente equânime, igualitário, participativo e inclusivo, fazendo referência à gestão democrática. Eis, portanto, o desafio!

\section{Referências}

ABRANCHES, M. Colegiado escolar: espaço de participação da comunidade. São Paulo: Cortez, 2003.

BALL, S.J. Diretrizes políticas globais e relações políticas locais em educação. Currículo Fronteiras, v.1, n.2, p.99-116, 2001.

BALL, S.J. Education reform: a critical and post-structural approach. Buckingham, Philadelphia: Open University Press, 1994.

BALL, S.J. La micropolítica de la escuela: hacia uma teoria de la organización escolar. Barcelona: PAIDÓS, 1989.

BOGDAN, R.; BIKLEN, S. Investigação qualitativa em educação: uma introdução à teoria e aos métodos. Portugal: Porto, 1994.

BORDIGNON, G.; GRACINDO, R.V. (Org.) Gestão da educação: o município e a escola. In: FERREIRA, N.S.C.; AGUIAR, M.Â. Gestão da educação: impasses, perspectivas e compromisso. São Paulo: Cortez, 2001.

BOWE, R.; BALL, S.J.; GOLD, A. Reforming education and changing schools: case studies in policy sociology. London: Routledge, 1992.

BRASIL. Constituição Federal de 1988. Brasília, 1988.

BRASIL. Lei de Diretrizes e Bases da educação Nacional (1996). Biblioteca Digital da câmara dos deputados. Lei no 9.394 de 20 de dezembro de 1996.

BRASIL. Lei no ${ }^{\circ}$ 13.005, de 25 junho de 2014: Plano Nacional de Educação. Brasília, 2014.

BRASIL. Plano Nacional de Educação em Direitos Humanos. Secretaria de Direitos Humanos da Presidência da República, 2006.

BRASIL. Resolução CNE/CEB n. 5, de 22 de junho de 2012, que Define Diretrizes Curriculares Nacionais para a Educação Escolar Indígena na Educação Básica. Brasília: CNE, 2012.

CASTRO, A.M.D.A. A qualidade da educação básica e a gestão da escola. In: FRANÇA, M.; BEZERRA, M.C. (Org.). Politica educacional: gestão e qualidade do ensino. Brasília: Líber Livro, 2009.

FERREIRA, N.S. Gestão democrática da educação: ressignificando conceitos e possibilidades. In: FERREIRA, N.S.C.; AGUIAR, M.A. (Org.). Gestão da educação: impasses, perspectivas e compromissos. São Paulo: Cortez, 2001.

GALINA, I.F.; CARBELLO, S.R.C. Gestão democrática e instâncias colegiadas. In: CARVALHO, E.J. et al. (Org.). Gestão escolar. Maringá: Secretaria de Estado da Educação do Paraná / Universidade Estadual de Maringá, 2008.

GIL, A.C. Métodos e técnicas de pesquisa social. São Paulo: Atlas, 2008.

LIBÂNEO, J.C. Organização e gestão da escola: teoria e prática. Goiânia: Alternativa, 2001.

LIMA, L.C. A escola como organização educativa: uma abordagem sociológica. São Paulo: Cortez, 2011.

LÜCK, H. A gestão participativa na escola. Petrópolis: Vozes, 2013a.

LÜCK, H. Concepções e processos democráticos de gestão educacional. Petrópolis: Vozes, 2013.

MAINARDES, J. Reinterpretando os ciclos de aprendizagem. São Paulo: Cortez, 2007.

MARQUES, L.R. A descentralização da gestão escolar e a formação de uma cultura democrática nas escolas públicas. 
Recife: UFPE, 2007.

MINAYO, M.C. O desafio do conhecimento: pesquisa qualitativa em saúde. São Paulo: Hucitec, 2010.

PARO, V.H. Eleição de diretores de escolas públicas: avanços e limites da prática. In: PARO, V.H. Escritos sobre a educação. São Paulo: Xamã, 2001.

PPP - Projeto Político Pedagógico Da Escola Municipal Indígena João Lino da Silva/SEEC-RN. Outubro 2015. Canguaretama-RN: [s.n.], 2015.

REGIMENTO ESCOLAR DA ESCOLA MUNICIPAL INDÍGENA JOÃO LINO DA SILVA/SEEC-RN. Novembro 2015. Canguaretama-RN: [s.n.], 2015.

SILVA, G.; SILVA, A.V.; SANTOS, I.M. Concepções de gestão escolar pós-LDB: o gerencialismo e a gestão democrática. Rev. Retratos Esc., v.10, n.19, p.533-549. 2016.

SILVA, K.V. A. Gestão democrática escolar: uma experiência em duas escolas públicas na rede municipal de João Pessoa-Paraíba. João Pessoa: Universidade Federal da Paraíba, 2018.

SOUZA, A. Lisboa de. Participação e autonomia na escola: a eleição de diretor como espaço de articulação entre a teoria e a prática. In: CASTRO, A.M.D.A.; FRANÇA, M. (Org.). Política educacional: contextos e perspectivas da educação brasileira. Brasília: Líber Livros, 2012.

SPÓSITO, M.P. Educação, gestão democrática e participação popular. In: BASTOS, J.B. (Org.). Gestão democrática. Rio de Janeiro: DP\&A, SEPE, 2002.

VEIGA, I.P.A. Escola: espaço do projeto político pedagógico. Campinas: Papirus, 2005.

WERLE, F.O.C. Conselhos escolares: implicações na gestão da escola básica. Rio de Janeiro: DP\&A, 2003.

YIN, R.K. Estudo de caso: planejamento e métodos. Porto Alegre: Bookman, 2010. 